\title{
Urdimento
}

\section{MIMO E PANTOMIMA ${ }^{1}$}

\author{
Thomas Leabhart ${ }^{2}$ \\ Tradução e notas de Luciana Cesconetto Fernandes da Silva ${ }^{3}$
}

\section{Resumo}

Neste tex to o autor esboça brevemente a história do mimo desde a antiguidade até o inicio do século XX, esclarecendo alguns fatores importantes para a construção do mimo moderno. O autor distingue a tradição da pantomima silenciosa do século XIX do mimo moderno identificando os motivos que geraram a compreensão equivocada do mimo como uma arte silenciosa.

Palavras-chave: mimo, pantomima, mimo corporal.

O nome Marcel Marceau tem sido sinônimo de mimo nas últimas décadas, e, muito embora ele ocupe uma pequena parte deste livro, é graças às suas extensivas turnês, desde o início da década de 50, que se deve grande parte do recente e vasto interesse nessa arte antiga. Ele e outros mimos como a Companhia Mummenschanz são os elementos mais visíveis de um retorno ao movimento expressivo que tem manifestações no teatro contemporâneo de Grotowski, Mnouchkine, Peter Brook e outros. Estes indivíduos e grupos que lideram a atenção do universo teatral derivam tanto de uma tradição que podemos delinear até os primeiros anos deste século, quanto do trabalho revolucionário do professor e diretor francês Jacques Copeau, e, subsequentemente, de seu pupilo Étienne Decroux assim como dos alunos deste: Jean Louis Barrault e Marcel Marceau. Os professores Jean Dasté e Jacques Lecoq também provêm diretamente da escola de Copeau ${ }^{4}$. Eu devo distinguir a tradição da pantomima silenciosa do início do século XIX, pela qual Marceau é fortemente influenciado, do mimo moderno que usa sons, palavras, assim como movimentos metafóricos.
${ }^{1} 0$ presente artigo consiste na introdução do livro Modern and post-modern mime, de Thomas Leabhart

(1987, p. 1-16).

${ }^{2}$ Thomas Leabhart foi aluno e assistente de Étienne Decroux entre 1968 e 1972.

É editor do Mime Journal e Professor de Teatro no Pomona College (Califórnia). Leabhart ministra frequentemente cursos de Mimo Corporal em Paris através da Associação Hippocampe e é membro da ISTA (International School of Theatre Anthropology).

${ }^{3}$ Luciana Cesconetto

Fernandes da Silva é professora da Universidade Federal de Pelotas.

${ }^{4} J$ ean Dasté foi aluno de Jacques Copeau e ator na Companhia do Vieux-Colombier dirigida por Copeau. Jacques Lecoq trabalhou diretamente com Jean Dasté [N. da T.]. 


\section{Urdimento}

Visto que a tradição da tão conhecida pantomima evita sons e palavras, será útil esboçar brevemente a história do mimo até o início do século XX, isto é, até a escola de Copeau.

O silêncio no mimo é uma questão importante. $\mathrm{O}$ mimo necessita ser silencioso? Brendan Gill escreveu no New Yorker de 28 março 1983:

No coração da pantomima está a angústia sublimada da fala perdida; mesmo quando nós estamos sendo entretidos, nós mensuramos esta perda e sentimos pelo performer mudo a simpatia despertada por qualquer profunda e inescapável omissão. Estar na presença de um silêncio não natural, imposto, é efetivamente render-se à condição de surdo; se Marceau não tivesse tomado o cuidado de incluir acompanhamento musical nas suas estranhas narrativas não-verbais, eu me pergunto se nós não iriamos rapidamente achá-las insuportáveis.

Parece-me, todavia, que a maioria do mimo, do início dos tempos até o presente, tem sido acompanhada por algum tipo de som: falas providas pelo narrador, pelo coro ou pelo mimo; sons percussivos produzidos pelo choque de uma parte do corpo contra o outro ou contra o chão; ou o tipo de mimo vocal que os estudantes de Copeau experimentaram, usando ruídos pré e pósverbais, risos e outros sons expressivos que não são palavras. Em 1890 foi encontrado um pergaminho com 13 peças de mimo escritas por Herondas, um escritor grego que viveu na Alexandria por volta de 270 a.C. (ver The Mimes of Herondas, tr. Guy Davenport, 1981). Essas miniaturas de dramas espirituosos e às vezes depravados parecem confirmar que no mundo antigo ao menos alguns performers chamados mimos falavam, e até mesmo memorizavam textos escritos por outros. E mesmo quando os performers pantomimos (distintos dos performers mimos) não falavam, as suas performances eram raramente desacompanhadas de palavras, canções e música instrumental. Alguns poetas antigos também recitavam seus próprios trabalhos e acompanhavam os recitais com gestos expressivos. Diz a lenda que Livius Andronicos, ao perder sua voz em 240 a.C, contratou um ator para recitar enquanto este desenvolvia a parte gestual de sua performance. Ainda que esta história seja apócrifa, alguém sentiu a necessidade de inventá-la para explicar por que os performers mimos individuais seriam silenciosos, se em função da adversidade ou da escolha estética, enquanto as performances em si geralmente tinham algo verbal bem como componentes musicais.

Um livro publicado em Paris em 1751 entitulado Recherches historiques et critiques sur les mimes et sur les pantomimes [Pesquisas históricas e críticas sobre os mimos e as pantomimas] indica, pelo seu título, que o autor, Jacques Méricot, considerou que existia alguma diferença entre os dois termos "mimo" 


\section{Urdimento}

e "pantomima", expressões hoje utilizados frequentemente de forma aleatória. Méricot sugeriu que a pantomima era inteiramente silenciosa enquanto o performer mimo era acompanhado por um ator que falava por ele. Essa separação permitiu à pessoa que se movia desenvolver-se mais plenamente $\mathrm{e}$ à pessoa que fazia uso da palavra a falar sem perder a respiração. Tal arranjo permite especular que possivelmente os primeiros performers do Bharata Natyan (dança-teatro do sul da Índia) eram contadores de histórias que as ilustravam com gestos e danças e, como a dança foi se tornando mais complexa e atlética, as partes vocais foram tomadas pelos cantores profissionais.

Willson Disher atribuiu a suposição corrente de que a pantomima é silenciosa à Duchesse du Maine [Duquesa du Maine], que em 1706, querendo

glorificar as Nuits des Sceaux ${ }^{5}$, decidiu apresentar o quarto ato de 'Horácio' de Corneille como um ballet de Mouret [...]. Fora do conceito literário ela chamou isto de "Balé-Pantomima". Sua reivindicação era de que o show-mudo era uma arte pertencente aos antigos. Nenhum savant indicou que 'imitador de tudo' não significa alguém sem palavras. ... Os galantes lexicógrafos da Inglaterra, daquele dia até este, insistem que pantomima significava showmudo simplesmente porque a Duquesa du Maine disse que o era (DISHER, 1925, p. 225).

Embora na maioria dos períodos o mimo e a pantomima incluem alguma forma de palavra produzida por um primeiro ou segundo performer, além da música e dos sons percussivos produzidos pelos performers ou músicos, existem alguns períodos importantes nos quais a pantomima ocorreu sem textos falados em função de sanções governamentais que os proibiram em certos teatros. Essas restrições produziram uma forma de performance que pode ser bela e completa em si mesma. Contudo, em função destes períodos relativamente breves, esperar que todo mimo deva ser silencioso é o mesmo que pensar que todos dançarinos devam usar sapatilhas de pontas. Mesmo assim, enquanto eu escrevo estas palavras, a maioria do público que vai ao teatro, a maioria dos historiadores e a maioria dos performers mimos vão definir mimo como uma história contada silenciosamente. Por quê?

Luis XIV expulsou os atores italianos de Paris em 1697 porque, dizem, estes zombaram da sua amante, Madame de Maintenon. A rivalidade entre atores italianos por um lado, e a Comédie Française e o Opéra (os teatros dos reis) por outro lado, gerou um descontentamento de proporções tão ardentes que os atores italianos (exilados para a Margem Esquerda ${ }^{6}$ ) foram liberados pelas autoridades a atuar com a condição de que os atores não falassem. Por volta de 1700 a pantomima silenciosa teria então nascido e os franceses
${ }^{5}$ Foram chamadas de Nuits des Sceaux as festas grandiosas que a Duquesa du Maine deu entre 1714 e 1715 no castelo e nos jardins de Sceaux (Ile-de-France). Nestas festas eram apresentadas óperas, balés, peças e poemas como divertimentos [N. da T.].
${ }^{6}$ Trata-se da Rive Gauche: margem esquerda/margem sul do Sena, região não elitizada onde concentravam-se artistas e intelectuais de Paris [N. da T.]. 


\section{Urdimento}

mostrariam mais uma vez seu gênio para impor suas misteriosas restrições e então, triunfantemente, inventaram formas astutas de cerceá-los. Em 1716 o banimento foi suspenso e os atores italianos foram aceitos de volta à Paris, no entanto, a quantidade de teatros assim como o gênero teatral permitido ainda eram controlados. Em 1750 o Boulevard du Temple, então no subúrbio de Paris, se tornou a área oficial dos teatros de feira, os quais foram restritos de diferentes formas: o primeiro teatro licenciado deveria apresentar somente dança na corda, e cada um subsequentemente tinha outra árdua limitação. A área se transformou rapidamente numa atmosfera de carnaval: números com animais, marionetes, malabaristas, acrobatas e arlequinadas enchiam as ruas, que eram margeadas por cabarés e cafés. Isto deve se parecer muito com a imagem reproduzida no filme Les enfants du paradis. A restrição mais absurda foi, possivelmente, uma que exigia que os atores representassem atrás de uma tela de gaze. Quando o ator Plancher-Valcour soube, em 14 de julho de 1789, que a Bastilha havia sido tomada, ele se atirou através da tela de gaze gritando "salve a liberdade" (ROOT-BERNSTEIN, 1984, p. 178).

Na Inglaterra em 1717, o ator John Rich foi atraído por esta novidade francesa já que ele tinha menos habilidade para falar do que para gesticular. Ele popularizou rapidamente a nova pantomima silenciosa na Inglaterra, e as inovações inglesas por sua vez influenciaram os franceses. Rapidamente os grupos itinerantes de pantomimas estavam representando na França, Holanda, Alemanha, Áustria e Dinamarca.

As restrições legais determinaram o repertório, o tamanho do elenco, o número de músicos. Foi somente em 1791 que o diálogo ou as canções puderam ser incluídas na pantomima que persistiu na França. Apesar das sanções oficiais, o entretenimento popular floresceu: trinta e cinco teatros foram construídos no Boulevard du Temple por esta época. O número cresceu para 100 depois que a Assembléia Nacional retificou decretos em janeiro de 1791 permitindo a qualquer cidadão estabelecer um teatro público e apresentar peças de qualquer tipo. Neste período, diálogos e canções, os quais haviam sido privilégio apenas dos teatros dos reis, foram imediatamente incluídos nas pantomimas para produzir um novo gênero híbrido chamado "melodrama" (CARLSON, 1974, p. 27).

Restrições foram impostas novamente em 1807 por Napoleão, que regulamentou o número de teatros em Paris bem como os seus gêneros e repertório, e Jean-Gaspard Deburau começou sua meteórica carreira em 1819 no Théatre des Funambules no Boulevard du Temple. A dinastia que ele estabeleceu continuou pelo início dos anos 1920, muito embora as restrições na fala tenham sido eliminadas ainda na época de Deburau. 
No final do séc. XIX na França, a rigidez acadêmica foi arrastada para dentro do teatro, do mimo e da dança. O gênio de Deburau foi substituído por uma longa sucessão de imitadores que recriaram a forma extrema, mas perderam a chama interna; a pantomima tornou-se um assunto de mãos e rosto, o corpo coberto por volumosas vestimentas. A dança no Opéra de Paris, reduzida a estátuas posando com música, apoiava-se fortemente nas extremidades do corpo, enquanto o torso era rigidamente preso por espartilhos. O teatro naquele tempo foi uma exaltação das personalidades de certas estrelas, cercadas por atores medíocres. A época era oportuna para mudanças, e, se as coisas não estavam tão ruins quanto os revolucionários as pintaram, havia ao menos alguma verdade nas reivindicações a ponto de a renovação ter sido uma necessidade imperiosa. Esta renovação, no entanto, não veio de dentro das artes em questão, mas como um resultado dos novos interesses da ciência, da tecnologia e do esporte. A preocupação do séc. XIX em "estabelecer e descrever (...) os reais fatores da locomoção animal em geral e da locomoção humana em particular" (SPARSHOTT in SOURRIAU, 1983, p. ix) pode ser vista no trabalho da pesquisa do movimento independente, trabalho este que, iniciado no século XIX, teve um efeito significativo no mimo, no teatro e na dança do século XX.

Eadweard Muybridge nascido Edward Muggeridge em 1830 na Inglaterra, começou fotografando movimentos em Palo Alto, Califórnia, em 1872, quando Leland Stanford, um antigo governador da Califórnia, providenciou fundos para Muybridge fotografar a corrida de cavalos de Stanford a fim de ver se todas as quatro patas deixavam o chão simultaneamente. Nestes experimentos, Muybridge desenvolveu uma técnica de utilização de vinte e quatro câmeras para fazer fotos de ação sequencial. Ele continuou sua pesquisa na Universidade da Pensilvânia, onde foi patrocinado pelo pintor Thomas Eakins e por volta de 1885 ele já tinha produzido 100.000 fotografias de cavalos, de animais domésticos e selvagens, e seres humanos. O seu trabalho assim como o do francês Jules Marey, autor de La machine animale [A máquina animal], usaram novas tecnologias para expandir o conhecimento do movimento em áreas que ultrapassavam a percepção humana normal. Muybridge palestrou nos EUA e Europa utilizando um zoopraxiscope, um instrumento que ele inventou para mostrar slides de vidro numa rápida sucessão, criando o efeito de movimento. Em 1887 ele publicou Animal Locomotion [Locomoção animal], em 1889 Animals in Motion [Animais em movimento], e em 1901 The Human Figure in Motion [A figura humana em movimento]. Sua documentação sobre o que ocorria no movimento natural foi uma revelação para aqueles cuja profissão era a representação da forma estilizada ou teatral deste movimento. Thomas Eakins foi demitido de seu trabalho como professor em uma escola de arte por usar modelos nus; no quarto 


\section{Urdimento}

de século seguinte, dançarinos e mimos praticamente nus se apresentaram no palco. Escultores como Rodin, na França, preferiram trabalhar com modelos nus em movimento do que com os moldes de gesso com os quais se aprendia a desenhar nas academias. Isadora Duncan se apresentou para Rodin, que a desenhou enquanto ela dançava no seu estúdio.

O filosofo francês Paul Souriau nasceu em 1852. Como Muybridge, ele tentou entender o movimento, porém com a filosofia ao invés de câmeras como ferramenta. Um de seus principais trabalhos intitulou-se The Aesthetics of Movement [A estética do movimento]. Souriau entendeu Gustave Eiffel, seu contemporâneo, que tinha perguntado, "As atuais condições de força não estão sempre de acordo com as condições secretas da harmonia? O primeiro princípio da estética arquitetural é que as linhas essenciais de um movimento sejam determinadas pela adequação perfeita das suas intenções" (SOURRIAU, 1983, p.100). Isso mostra a atmosfera que destruiu as academias do século XIX.

François Delsarte ensinou voz para a oratória e para a representação teatral, em Paris, de 1839 até 1871. Aos catorze anos ele foi admitido no Conservatório em Paris para estudar voz, apesar de sua pouca idade e dos requisitos para entrar nesta instituição. Em seis meses, como consequência de um ensino impróprio, ele perdeu sua voz. Destemido, ele se propôs a descobrir a ciência por trás da arte. Ele criticou o treinamento dado no Conservatório como mera imitação do professor, e observou que os docentes estavam muitas vezes em desacordo. Ele concluiu que "nenhuma teoria sustentaria a execução", e se lançou na "conquista da ciência que faria de mim um grande artista” (STEBBINS, 1977, p. 445). Os ensinamentos de Delsarte tiveram que viajar aos EUA para, através de Ted Shawn, Ruth St. Denis e Isadora Duncan, influenciar a dança moderna americana antes de, finalmente, provocar algum efeito na dança do Opera de Paris, um quarto de século mais tarde. Shawn, St. Denis e Isadora apresentavam-se praticamente nus naquela época, e seus experimentos corajosos com figurinos leves e soltos estavam em oposição direta ao estilo de roupas e à moralidade daquele tempo. Seus exemplos ajudaram a libertar os corpos de homens e mulheres dos espartilhos, sapatos e outras roupas apertadas, e, algo que muitas vezes esquecemos, lembrar às pessoas quão linda e graciosamente o corpo pode se mover quando este não está refreado. Eles incorporaram as imagens de Muybridge, conectando suas fotografias de homens e mulheres nuas com movimentos tão fluidos quanto o seu zooprazciscope era capaz de produzir. As aplicações dos princípios de Delsarte libertaram o torso como um elemento expressivo, permitindo ondulações desta parte do corpo que antes era rigidamente contida. A escala dinâmica de tensão-relaxamento da dança moderna, baseada na lei de Delsarte da reação-recuo é comparável ao princípio da respiração muscular encontrada no mimo moderno. O uso criativo de massa, peso e gravidade é tão importante 
no mimo moderno como o é na dança moderna. A afirmação de Shawn de que os movimentos abstratos da dança moderna são baseados em gestos concretos, ecoa da alegação de Decroux de que "O abstrato é a flor do concreto". O grande interesse de Decroux nos contrapesos tem um respaldo na lei de Delsarte do equilíbrio, o qual esboça quatro tipos de ajustes que o corpo faz em resposta para certos esforços (SHAWN, 1954, p. 64-71).

Um culto às ginásticas tomou conta da Europa no século XIX (a fim de manter a população em boa forma para a guerra e como um antídoto às debilidades físicas nos trabalhos fabris). Um dos principais expoentes franceses deste movimento foi o Tenente Georges Hébert, contemporâneo de Copeau quando este abriu sua escola no início do século XX. Hébert desenvolveu um sistema de educação física e de análise do movimento que Copeau incluiu no currículo da escola do Vieux-Colombier em 1922-23 (LEIGH, 1979, p. 34). A obra L'Éducation physique de l'entrainement complet par la méthode naturelle [A educação física do treinamento completo pelo método natural] de Hébert inclui diagramas cena por cena (de acordo com o método de Muybridge) da forma natural de representar movimentos esportivos. Alguns anos mais tarde Étienne Decroux criou um número substancial de modelos de ensino para sua técnica do mimo moderno através da análise dos movimentos dos esportes na sua forma de composição parte por parte.

Paul Bellugue, que foi professor de anatomia na École des Beaux Arts em Paris, de 1936 até 1955, é a última das nossas maiores figuras que ajudou a pavimentar o caminho do mimo moderno. Bellugue proferiu muitas vezes demonstrações de leitura sobre dança e esportes com a assistência de Étienne Decroux, que ilustrava alguns dos princípios descritos por Bellugue. Quando este escrevia "A beleza é a forma visível do gesto econômico", ele repetia Souriau citando Eiffel. Ambos, Decroux e Jacques Lecoq, o qual começou sua carreira como professor de educação física e terapia física, citaram largamente Bellugue. Este dedicou uma grande parte de sua carreira à análise dos esportes, da dança e da escultura. Sua afirmação de que "A cultura do dançarino e a do atleta se embasa nos mesmos princípios: simplificação, depuração e organização dos gestos" (BELLUGUE, s.d., p. 110) é uma afirmação com a qual ambos, Decroux e Lecoq, concordaram imediatamente.

A revolução industrial do séc. XIX naturalmente gerou o interesse na análise dos movimentos como uma via de estabelecer uma eficiente interação entre o homem e a máquina. Não é de se surpreender que os artistas tenham passado a criar movimentos expressivos baseados nestas pesquisas, como em L'Usine [A Usina] de Decroux, em inúmeros outros futuristas, construtivistas assim como nos ballets mécaniques [ballets mecânicos] da Bauhaus. Jean Louis Barrault escreveu, "Não podemos hesitar em dizer: deve haver, no fundo de 


\section{Urdimento}

${ }^{7}$ Esta é a tradução literal para 0 português do termo traduzido do francês por Leabhart. Nos escritos de Copeau sobre a escola do Vieux-Colombier, no entanto, encontramos o termo "techniques mimiques" que significa literalmente "técnicas mímicas" [N. da T.].

${ }^{8}$ Decroux utiliza a expressão "Casa" no sentido de "seu próprio corpo" [N. da T.]. cada ator, um elemento do robô. A função da arte é a de conduzir este robô em direção ao natural; fazer, por meios artificiais, uma imitação da natureza. É porque o violino é uma caixa oca, como um corpo morto, que ele é tão satisfatório para ser preenchido com a alma” (BARRAULT, 1949, p. 29).

Isto se parece muito com a descrição de Paul Souriau sobre as três qualidades demandadas pelo movimento para que este tenha valor estético: "a beleza mecânica do movimento, sua expressão, e o prazer perceptível que ele oferece" (SOURRIAU, 1983, p. xx).

O mais importante de todos para uma compreensão do teatro contemporâneo e do mimo contemporâneo é o trabalho de Jacques Copeau. Este reagiu fortemente contra o que ele viu ser a decadência do teatro em Paris no início do século XX. Para vencer a debilidade que ele entendeu ser inerente ao sistema do estrelato, com suas atuações afetadas e insensíveis tratamentos dos textos, ele propôs um novo teatro com a "renormalização" do ator no seu centro. Este ator "renormalizado" deveria ser treinado para desaprender toda a artificialidade que ele havia adquirido. Para produzir o tipo de ator que ele requeria, Copeau fundou a École du Vieux-Colombier, a qual tinha um currículo calculado para dar aos atores um treinamento muito mais completo que aquele estreitamente especializado encontrado no Conservatório. Os alunos de Copeau estudavam literatura, história, fala, voz e ofícios do teatro, e tinha também uma forte ênfase no treinamento físico. Copeau acreditava que a agilidade física, o trabalho com a máscara, a atuação em grupo e a habilidade com o mimo estavam no coração das idades de ouro do teatro: os períodos que produziram as peças de Nô, os dramas gregos, os mistérios medievais, a commedia dell'arte, e as peças de Molière e de Shakespeare. O treinamento físico na École du Vieux-Colombier envolvia acrobacias, balé clássico, ginástica, esportes e trabalho com máscaras, então conhecido como mimo corporal ${ }^{7}$.

O estudo do mimo corporal com Copeau na École du Vieux-Colombier inspirou Étienne Decroux a dedicar sua vida à pesquisa das possibilidades expressivas do corpo humano depois que o trabalho do ator foi liberto da tirania do que Decroux chamou de "artes estrangeiras": literatura, cenário, música, dança, figurino e outras. Decroux, todavia, nunca tencionou que o teatro permanecesse sem voz; ele prescreveu a fala ordinária por um período de trinta anos, ou até que o ator tivesse tomado o comando de sua própria casa ${ }^{8}$, quando então as artes estrangeiras poderiam ser introduzidas novamente de acordo com a necessidade, estando o ator firmemente no controle.

Decroux, reagindo fortemente contra a pantomima de rosto branco que ele tinha assistido nos café-concerts quando criança, vislumbrou um mimo moderno que seria um registro tão claro e belo da essência como o são as 
pinturas de Mondrian e a escultura de Brancusi, dois dos contemporâneos de Decroux. E, embora Decroux tenha trabalhado inicialmente com a pantomima ilusionista (mimo objetivo), seu trabalho posterior foi mais subjetivo, explorando caminhos da expressão do pensamento em movimento, estudando a forma que o pensamento esculpe o corpo, e examinando com grande detalhe a maneira com que o esforço físico forma o corpo (contrapesos). O esforço do homem de Prometeu contra a gravidade singularizada em qualquer situação dramática específica é central no trabalho de Decroux, o qual tem sido, por cinquenta anos, diametralmente oposto ao entretenimento encantador ou humorístico. Embora Decroux tenha uma carreira longa e cheia de sucesso como um ator de palco, tela e rádio, suas performances de mimo não encontraram grande aclamação do público, talvez em função de sua tendência ao abstrato, à sua estrutura não linear que encontramos na maioria dos trabalhos modernistas em outras artes. A maior contribuição de Decroux ao mimo foi como professor, inventor da técnica do mimo corporal e como teórico.

Jean-Louis Barrault trabalhou de forma muito próxima a Decroux quando este desenvolveu o mimo corporal. A improvisação, para a qual Barrault trouxe grande habilidade física e considerável imaginação, foi uma parte vital do trabalho deles, e suas primeiras descobertas foram catalogadas e classificadas por Decroux. Depois de um período de trabalho criativo utilizando as descobertas do mimo moderno, incluindo mimo vocal, Barrault escolheu continuar seu trabalho no teatro falado.

Depois da Segunda Guerra Mundial, outro brilhante aluno de Decroux começou sua carreira no mimo: Marcel Marceau. Depois de seus estudos com Decroux, este desenvolveu um personagem chamado Bip que é mais próximo do paradigma do século XIX da pantomima branca silenciosa que do mimo desenvolvido por Decroux. Marceau tornou-se o mais brilhante e bem conhecido performer de pantomima silenciosa de nosso tempo ou talvez de todos os tempos.

Logo após a Segunda Guerra Mundial Jacques Lecoq iniciou seu trabalho como professor de educação física, e, através de estudos com Jean Dasté e outros que entenderam a teoria e a prática da École du Vieux-Colombier, desenvolveu aspectos das redescobertas de Copeau no seu próprio ensino que é tão influente. Lecoq valorizou o trabalho da máscara neutra e expressiva, a improvisação e a commedia dell'arte, e é principalmente responsável pelo renascimento do clown como um artista de teatro. Sua pesquisa mais recente focou sobre o bufão.

É claro que a performance silenciosa também é associada com o início do cinema, onde a doce adversidade da tecnologia limitada proporcionou um forte estímulo às carreiras de Chaplin, Keaton e muitos outros. Ironicamente, 


\section{Urdimento}

foi um filme falado feito durante a ocupação germânica na França em meados dos anos 40 que determinou a carreira de Marceau e, consequentemente, nossa compreensão comum e equivocada do mimo como "contação de história silenciosa”. Les enfants du paradis, um clássico criado por Marcel Carné e Jacques Prévert, recriou a vida e os tempos de Jean-Gaspard Debureau. Jean-Louis Barrault, o ator e mimo francês que estudou com Decroux, atuou no filme como Debureau. Decroux também atuou na obra como o pai de Debureau. Neste filme tremendamente popular e altamente aclamado, Decroux e Barrault recriaram o mimo branco ilusionista e silencioso de um período inicial; é importante observarmos quanta mudança ocorreu nesta pintura, grande parte em função da pesquisa do mimo moderno que Decroux e Barrault estavam então fazendo.

Quando o filme ganhou seu primeiro sucesso popular, o jovem Marceau, um aluno de Decroux no fim dos anos 40, teve aí uma visão do que sua própria carreira poderia tornar-se. Verdadeiro com sua intuição, Marceau foi ser para o século XX o que Debureau foi para o século XIX. Marceau extraiu muito da tradição francesa do século XIX assim como da pesquisa do mimo ilusionista que Decroux estava então fazendo, mas que rapidamente repudiou. A outra fonte primária da síntese brilhante de Marceau foi a representação silenciosa de Chaplin e de Keaton.

O paradigma de Marceau dominou o campo. Seu nome foi, por décadas, sinônimo de mimo. Através de várias idas e vindas da história, os breves períodos nos quais o mimo foi silencioso são relembrados na sua performance silenciosa. A era pós Marceau no mimo é certamente mais vista como um retorno à tendência atual desta arte. $\mathrm{O}$ mimo que assistimos em festivais internacionais em todo o mundo, o mimo que deriva principalmente da pesquisa e técnica de Lecoq e Decroux, é tão distante da "contação de história silenciosa" quanto pode ser imaginado, e, como temos visto, nisto ele reconcilia-se com o mimo conforme ocorreu na maioria dos períodos da história. Registros dos períodos Romanos e Gregos relacionam, em sua grande maioria, a pantomima e o mimo com a fala e a narração cantada, tanto através do performer mimo quanto por outro ator ou pelo coro. Indubitavelmente os teatros orientais fundamentaram-se cedo nisto. Como os elementos vocais e de movimento da performance foram ampliados e voltaram-se para a virtuosidade, tornou-se incrivelmente necessário para eles organizarem-se em performers especialistas ao invés de manteremse como contadores de histórias solo fazendo tudo. Alternativamente, onde havia somente um performer, a apresentação organizava-se melhor, por exemplo, não coincidindo a maior parte da demanda vocal com o movimento mais acrobático. 
Durante os tempos medievais o mimo muitas vezes foi apresentado por menestréis vadios ou atores de vida errante, ou como parte de dramas seculares ou religiosos. Novamente, parece raro ter sido silencioso. A commedia dell'arte, uma forma de teatro baseada na improvisação e contendo movimentos vigorosos e acrobáticos assim como diálogos fixos e improvisados, foi imensamente popular por toda a Europa desde o século XVI até o século XVIII. Este teatro tem muito em comum com os primeiros tipos mencionados acima: ele era apresentado ao ar livre, usava máscaras, e era normalmente o esforço de um grupo itinerante trabalhando junto numa família fechada ou em um grupo semelhante a uma família.

O mimo branco silencioso, como nós acabamos de entender, fez suas primeiras aparições na década de 20 do século XIX, quando Jean-Gaspard Debureau tornou-se o ator mais popular de seu tempo com suas pantomimas de Baptiste. Ele floresceu em um teatro cercado por restrições governamentais impostas primeiro por Louis XIV, continuaram através dos reinados de Louis XV e Louis XVI, e mais tarde foram revividas por Napoleão. Estas restrições criaram as pantomimas silenciosas nas quais as partes de textos necessárias eram fornecidas por placas ou por músicas cantadas pelo público [...]. Quando estas restrições governamentais foram finalmente eliminadas depois da morte de Debureau, a forma na qual ele se sobressaiu continuou por alguns anos, e a corrente em voga da atividade teatral consistiu nos melodramas, operetas e outros entretenimentos populares que utilizavam canções e falas. O estilo de movimento exagerado que nós muitas vezes associamos ao melodrama ocorreu sem dúvida como um resultado do período no qual os entretenimentos populares eram privados de fala.

Marceau e, antes dele, Debureau levaram a pantomima branca ilusionista às suas maiores extensões; o mimo contemporâneo voltou-se ao modelo da síntese assim como os performers pós-modernos incluíram a palavra, canções e outros elementos teatrais no seu trabalho. Fazendo isso, eles começaram a assemelhar-se aos mimos dos tempos medievais e antigos que falavam ou que eram acompanhados por falas ou textos cantados, recitados por narradores ou pelo coro. À medida que examinamos o mimo desde 1900 até o presente, nós descobrimos que o mimo não é uma disciplina rara e totalmente separada da tendência atual do teatro, mas sim uma forma multifacetada de expressão a qual está no coração do teatro - um teatro do ator criativo que determina a síntese do movimento, texto, música, luz e cenário. O mimo revelase como o berço do movimento, tanto quanto dos impulsos vocais através dos quais o ator-criador expressa primeiramente os estados internos. Muito mais que uma diversão suficientemente agradável, muito mais que um show-mudo, o mimo constitui de fato as entranhas do teatro. 


\section{Urdimento}

\section{Referências bibliográficas}

BARRAULT, Jean-Louis. Child of silence, tr. Eric Bentley, Theatre Arts, 28-31, Out. 1949.

BELlugue, Paul. A propos d'art de forme et de mouvement. Paris: Librairie Maloine, s. d. .

CARLSON, Marvin. The Golden Age of the Boulevard. Drama Review, 18, no. 1, 25-23, 1974.

DISHER, M. Willson. Clowns and Pantomimes. London: Constable, 1925.

LEABHART, Thomas. Modern and post-modern mime. New York: St. Martin’s Press, 1997.

LEIGH, Barbara Kusler. Jacques Copeau's School for Actors. Mime Journal, Allendale, Mich., 1979.

ROOT-BERNSTEIN, Michele. Boulevard Theatre and Revolution in Eighteenth Century Paris. Ann Arbor: University of Michigan Research Press, 1984.

SHAWN, Ted, Every Little Mouvement. Pittsfield, Mass.: Eagle Printing, 1954.

SOURRIAU, Paul. The aesthetic of mouvement. Amhest: University of Massachusetts Press, 1983.

STEBBINS, Genevieve. Delsarte System of Expression. New York: Dance Horizons, 1977. 